\title{
UMA FERRUGEM DA ACÁCIA-NEGRA NO BRASIL
}

\author{
ÁLVARO F. SANTOS ${ }^{1} \&$ FRANCISCO A. FERREIRA ${ }^{2}$
}

${ }^{1}$ Centro Nacional de Pesquisa de Florestas, EMBRAPA, Cx. Postal 319, 83411-000, Colombo, PR, e-mail: alvaro@cnpf.embrapa.br; ${ }^{2}$ Departamento de Fitopatologia, Universidade Federal de Viçosa, 36571-000 Viçosa, MG

(Aceito para publicação em 29/05/2001)

Autor para correspondência: Álvaro F. Santos

SANTOS, A.F. \& FERREIRA, F.A. Uma ferrugem da acácia-negra no Brasil. Fitopatologia Brasileira 27:099-100. 2002.

\section{RESUMO}

Relata-se, pela primeira vez, a ocorrência de uma ferrugem em acácia-negra (Acacia mearnsii) no Brasil, identificada, morfologicamente, como fase uredinial da ferrugem foliar Uromycladium alpinum. O fungo causa leve amarelecimento e queda dos folíolos de árvores com dois anos de idade em plantações nos municípios de Cristal, Piratini e Encruzilhada do Sul, RS. Os danos em conseqüência dos surtos dessa ferrugem foram de baixa intensidade. Ressalta-se também que não há, até então, nenhum relato de ocorrência de ferrugem nesse hospedeiro nos países vizinhos do cone Sul.

Palavras-chave adicionais: Acacia mearnsii, Uromycladium alpinum.

\section{ABSTRACT \\ A rust on Black wattle in Brazil}

It is being reported, for the first time, in South Brazil and South cone of South America, a rust occurrence on leaves of Black wattle (Acacia mearnsii). This rust has been morphologically identified as the uredinial state of
Uromycladium alpinum. The occurrence of this rust on the black wattle plantations of Rio Grande do Sul State has brought light damage. Until now, there are none report about this rust on $A$. mearnsii in South America.
A acácia-negra (Acacia mearnsii De Wild.) é uma leguminosa arbórea, originária da Austrália, que vem sendo cultivada em vários países, a partir do início deste século (Higa \& Dedecek, 1999). No Brasil, o estado que mais a cultiva é o Rio Grande do Sul, cujo estabelecimento da primeira plantação comercial deu-se por volta de 1930. Da casca da acácia negra extrai-se o tanino para as indústrias de curtume e sua madeira tem sido utilizada para energia, celulose e chapa de fibra. A área cultivada com essa essência no Rio Grande do Sul é de aproximadamente 100.000 ha, envolvendo cerca de 10 mil produtores (Fleig, 1993).

Mundialmente, várias enfermidades têm sido registradas afetando a cultura da acácia-negra (Roux et al., 1995). Dentre essas doenças, quatro ferrugens têm sido assinaladas: Uromycladium notabille (Ludw.) McAlp., $U$. bisporum McAlp., U. alpinum McAlp. e U. teppernianum (Sacc.) McAlp. Entretanto, não há unanimidade para o reconhecimento dessa última espécie (Roux et al., 1995). Além disso, dentre essas ferrugens, somente $U$. alpinum tem sido considerada exclusivamente foliar .

No Brasil, a cultura da acácia negra tem recebido muito pouca atenção fitopatológica, excetuando-se nesses últimos cinco anos. Atualmente, a enfermidade que se tem destacado como a mais importante dessa cultura no território brasileiro é a doença do tronco conhecida como gomose (Santos et al., 1998). Em 1999, observou-se uma ferrugem causando ligeiro amarelecimento e queda dos folíolos em plantações nos municípios de Cristal, Piratini e Encruzilhada do Sul, RS (Figura 1). Como nunca havia sido observado ataque de ferrugem à essa cultura no Sul do Brasil e países vizinhos do cone Sul da America do Sul, o objeto desta comunicação é relatar essa doença.

Os plantios de acácia negra afetados pela ferrugem nos municípios mencionados estavam com dois anos de idade e foram estabelecidos para serem monitorados quanto ao comportamento silvicultural e incidência de doenças e pragas. Os surtos de ferrugem que foram observados nessas plantações foram de baixa intensidade. Das amostras de folhas doentes coletadas, somente pústulas do estágio uredinial foram constatadas com o auxílio de microscópio esteroscópico e microscópio ótico comum. As uredínias observadas foram subepidermais, anfígenas, isoladas (100 a $250 \mu \mathrm{m}$ de diâmetro), ou agrupadas, espalhadamente, nos folíolos; eram destituídas de paráfises e seus urediniosporos (Figura 2) (23-42 X 14-23 $\mu \mathrm{m})$ apresentaram, caracteristicamente, quatro a cinco poros germinativos equatoriais, unizonados; junto ao hilo basal dos esporos observou-se pequeno pedaço remanescente do pedicelo ou hifa suporte (Figura 2). Essas características conduziram à conclusão de que a fase uredinial a ferrugem foliar da acácia negra no Brasil não difere, morfologicamente, daquela, também foliar, relatada na África do Sul, a qual foi identificada como fase uredinial de Uromycladium alpinum por Morris \& Wingfield (1988). 


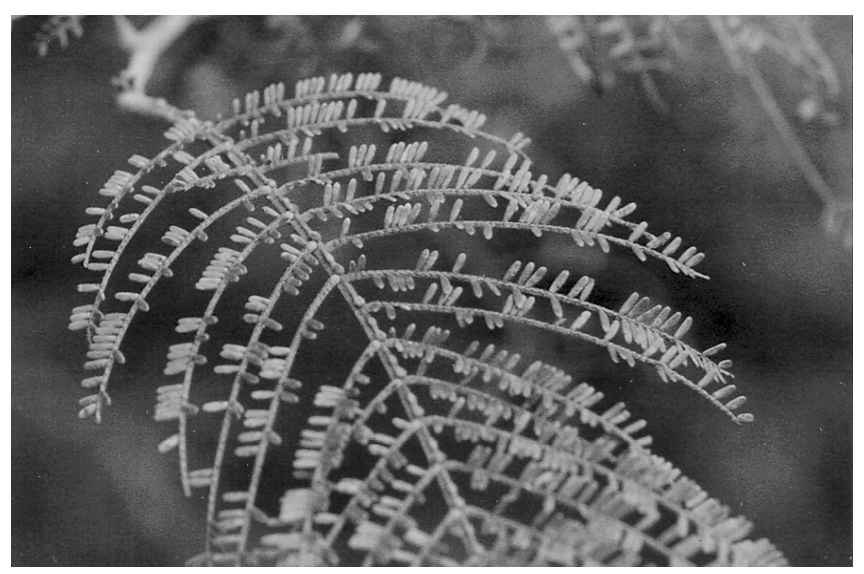

FIG. 1 - Sintoma da ferrugem em folíolos de acácia-negra (Acacia mearnsii).

\section{REFERÊNCIAS BIBLIOGRÁFICAS}

FLEIG, F.D. Análise econômica de sistema de produção co acácianegra (Acacia mearnsii De Wild.) no Rio Grande do Sul. (Tese de Mestrado) Santa Maria. Universidade Federal de Santa Maria, 1993.

HIGA, R.C.V. \& DEDECEK, R.A. Acácia negra. Colombo: EMBRAPA-CNPF, Instrução Técnica, 5. 1999.

MORRIS, M.J. \& WINGFIELD, M.J. First record of a rust on Acacia mearnsii in South Africa. Transactions of the British Mycological Society 90:324-327. 1988.

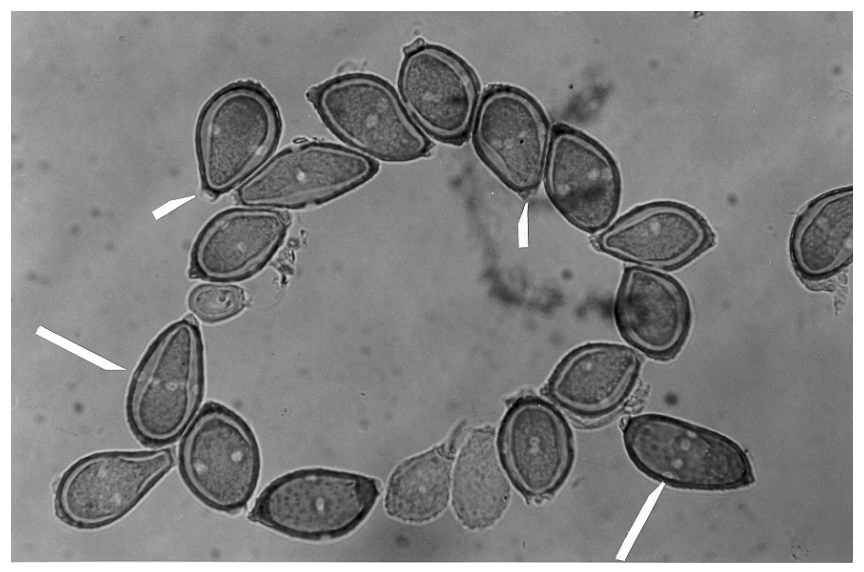

FIG. 2 - Urediniosporos de Uromycladium alpinum em acácia-negra (Acacia mearnsii). Setas maiores indicam vizualização de poros germinativos equatoriais, unizonados; setas menores, resquício de porção de pedicelar ou hifa-suporte.

RESENDE, S.J. Cultura da acácia negra (Acacia decurrens Wild var. molissima). Folha Florestal 28:1-7. 1971.

ROUX, J., KEMP, G.H.J., WINGFIELD, M.J. Diseases of Black wattle in South Africa - a review. South African Forestry Journal 174:35-40. 1995.

SANTOS, A.F., AUER, C.G., GRIGOLETTI, A. Caracterização de tipos de gomose da acácia-negra (Acacia mearnsii) no sul do Brasil. Boletim de Pesquisa Florestal 37:31-40. 1998. 